\title{
Practice Spotlight: Staff Development and Practice Evaluation Pharmacist
}

\author{
Colette Raymond, PharmD, MSc \\ Staff Development and Practice Evaluation \\ Pharmacist \\ Winnipeg Regional Health Authority \\ Pharmacy Program \\ Winnipeg, Manitoba
}

$\mathrm{T}_{\mathrm{n}}^{\mathrm{h}}$ The Winnipeg Regional Health Authority (WRHA) in Win-

nipeg, Manitoba (population catchments 800 000), consists of 5 acute care facilities, with capacity ranging from 185 to 745 beds, and 3 long-term care facilities. The WRHA Pharmacy Program consists of 7 separate pharmacy departments, with pharmacy staffing complements ranging from 13 to 121 full-time equivalents (FTE) (approximate total FTEs 300). The hospitals within the WRHA Pharmacy Program have different drug distribution and pharmacy information systems, but they have a common formulary and a common set of clinical practice expectations for pharmacists.

The terms "practice evaluation" and "research" can be used to describe many endeavours in institutional pharmacy practice. Practice evaluation and research can include numerous types of studies conducted by pharmacists or pharmacy technicians, such as literature reviews, descriptive studies, and hypothesisdriven research. ${ }^{2}$ Research and evaluation have been identified as constituting key areas for the future of pharmacy practice. ${ }^{3}$ Adequate mentorship, time, and resources and a sufficient number of trained researchers are important factors for the success of pharmacist clinician-researchers. It has been recommended that academic pharmacy practice departments develop a critical mass of clinical pharmacy scientists. ${ }^{3}$

In late 2007, under the leadership of Dr Kevin Hall, the WRHA Pharmacy Program funded the position of Staff Development and Practice Evaluation Pharmacist, and Dr Colette Raymond has held the position since then. Key responsibilities include developing education and training structures and processes that support staff in developing critical thinking skills; carrying out research and developing evaluation methodologies; executing projects; analyzing data and reporting results; assisting and mentoring pharmacy staff members who carry out practice research and evaluation; and planning, coordinating, and carrying out evaluative studies of pharmacy practice and pharmacy services within the WRHA.

Staff development activities have included conducting a needs assessment of pharmacy staff with regard to practice evaluation and research training and mentoring, ${ }^{4}$ conducting didactic sessions about practice evaluation and research skills, and providing one-on-one support to interested pharmacy researchers throughout the WRHA. Additional responsibilities include maintaining a database of ongoing projects (planned, initiated, and completed), along with appropriate approvals (e.g., approval from the relevant institutional review board or research impact committee); ensuring alignment of projects with national, regional, and Pharmacy Program goals (e.g., quality plan, CSHP 2015, Accreditation Canada); and developing project dissemination plans. Knowledge transfer activities include preparing an annual report of academic activities, highlighting research and evaluation projects conducted by staff on the intranet of the WRHA Pharmacy Program, and encouraging pharmacist and pharmacy technician researchers to present and publish their work.

The Staff Development and Practice Evaluation Pharmacist has worked with members of the WRHA Pharmacy Program team to conduct many evaluation projects. One key project is ongoing evaluation of organizational restructuring of the WRHA Pharmacy Program, which is moving toward technicianmanaged drug distribution. Other evaluation work involves educational initiatives of the WRHA Pharmacy Program, including orientation for new staff, ${ }^{5}$ a supervisory skills course for hospital pharmacy workplaces, ${ }^{6}$ prior learning assessments, professional development of technicians, ${ }^{7}$ and preceptorship rotation. Other pharmacy practice research has evaluated new or expanded pharmacist positions and funding ratios. ${ }^{8.9}$ Since the inception of this position, collaborative work involving pharmacy managers, the staff development team, and pharmacy staff members has led to an increase in the academic output of the Pharmacy Program (Table 1). Notable contributions include research projects conducted by novice researchers and pharmacy technicians. ${ }^{79-11}$

Some of the successes of this position relate directly to skill-building within the WRHA Pharmacy Program. Educators and mentors know the immense satisfaction associated with seeing learners achieve their goals and experience the pride 


\section{Table 1. Academic Activities within the Winnipeg Regional Health Authority (WRHA) Pharmacy Program}

\begin{tabular}{lccc} 
Category of Activity & $\mathbf{2 0 0 7}$ & $\mathbf{2 0 0 8}$ & $\mathbf{2 0 0 9}$ \\
\hline $\begin{array}{l}\text { Peer-reviewed publications, reports, and books } \\
\begin{array}{l}\text { Abstracts for presentations at meetings, including } \\
\text { presentations external to WRHA pharmacy departments }\end{array}\end{array}$ & $\mathbf{2 6}$ & 22 & 21 \\
\hline $\begin{array}{l}\text { Presentations within WRHA pharmacy departments, } \\
\text { including "lunch and learn" sessions for technicians and } \\
\text { pharmacy educational rounds }\end{array}$ & $\begin{array}{l}\text { Data not } \\
\text { available }\end{array}$ & 31 & 60 \\
\hline
\end{tabular}

that comes from sharing their work. However, no position is without challenges. Some pharmacy staff members within the WRHA Pharmacy Program have indicated that lack of time to organize and conduct a study is a major barrier to their participation in practice evaluation and research projects. ${ }^{4}$ Challenges also relate to the difficulty of obtaining funding to attend conferences, a major motivating factor for staff to pursue practice evaluation and research opportunities.

Future directions for the Staff Development and Practice Evaluation Pharmacist include ongoing evaluation of the position itself and of the academic output of the WRHA Pharmacy Program. As a result of the activities associated with this position, we hope to enhance the skills, knowledge, and attitudes of all pharmacy staff regarding research and evaluation. We also hope that pharmacists, technicians, residents, students, and patients will benefit from the increased interest in using data to continually evaluate and inform our individual practices.

\section{References}

1. Direct patient care guidelines: pharmacist performance expectations for acute care facilities. Winnipeg (MB): Winnipeg Regional Health Authority, Pharmacy Program; 2004.

2. Guidelines for institutional pharmacy research. Ottawa (ON): Canadian Society for Hospital Pharmacists; 1997.

3. American College of Clinical Pharmacy Research Affairs Committee; Fagan SC, Touchette D, Smith JA, Sowinski KM, Dolovich L, Olson KL, et al. The state of science and research in clinical pharmacy. Pharmacotherapy 2006;26(7):1027-1040.

4. Raymond CB, Woloschuk DMM. Development and use of a prior learning assessment survey about practice evaluation and research capacity in a regional pharmacy program [abstract]. Can J Hosp Pharm 2008;61(4):304.

5. Woloschuk DMM, Raymond CB. Multihospital collaborative orientation program for new hospital employees. Am J Health Syst Pharm 2010;67(2): 118-121.

6. Woloschuk DMM, Raymond CB. Development of a supervisory skills course for hospital pharmacy workplaces. Can J Hosp Pharm 2010;63(4): 295-303.
7. Hayes C, Woloschuk D, Raymond C. A regional continuing professional development program for hospital pharmacy technicians [abstract]. Can J Hosp Pharm 2009;62(4):342.

8. Raymond CB, Wazny LD, Sood A, Vercaigne L. Funding renal clinical pharmacy services. Nephrol News Issues 2010;24(6):40-41,45-47.

9. Falk J, Raymond CB. Role of the pharmacist in a presurgical clinic designed to optimize outcomes after elective total joint arthroplasty. Am J Health Syst Pharm 2010;67(16):1314-1317.

10. Caligiuri C, Staub M, Galloway L, Blydt-Hansen T. A computerized pharmacy generated medication reconciliation process for transfer from the intensive care unit reduces discrepancies and order writing time [abstract]. Can J Hosp Pharm 2009;62(4):345.

11. Mistri J, Miller P, Coates J. Establishing a process for pharmacy technician initiated medication histories in the emergency department [abstract]. Can J Hosp Pharm 2009;62(4):344.

\section{Acknowledgements}

The efforts of Dr Kevin Hall, Dr Donna Woloschuk, Dr Nick Honcharik, and $\mathrm{Dr}$ Al Eros in the development and ongoing support of this position are appreciated. The hard work of the numerous pharmacists and technicians within the WRHA Regional Pharmacy Program in developing and executing research projects is also much appreciated.-Colette Raymond

The Practice Spotlight series highlights the accomplishments of Canadian pharmacists with unique practices in hospitals and related health care settings. If you have a unique or innovative practice, or you know someone else who should be profiled, please submit your contact information to Mary Ensom, Editor of CJHP (cjhpedit@cshp.ca), and one of our Associate Editors will be in touch with you. 